\title{
Preparation of Vanadium Dioxide Thin Films with Adjustable Electric Field Intensity Transition Point
}

\author{
Shi-Hao SHAN ${ }^{1, a}{ }^{*}$, Qing-Guo WANG ${ }^{1, b}$, Zhao-Ming QU ${ }^{1, c}$, Wei CHEN $^{1}$ and \\ Ang $\mathrm{LI}^{1}$
}

\author{
${ }^{1}$ Institute of Electrostatic \& Electromagnetic Protection, Ordnance Engineering College, \\ Shijiazhuang 050003
}

a13032632585@163.com, bqingguowang99@aliyun.com, ciamqzm3990@163.com,

*Shan Shihao

\begin{abstract}
Keywords: Inorganic sol-gel method, vacuum annealing, electric field strength phase change point
\end{abstract} adjustable, vanadium dioxide thin film

\begin{abstract}
Preparation of phase change electric field adjustable vanadium dioxide thin films on $\mathrm{Al}_{2} \mathrm{O}_{3}$ ceramic substrates by inorganic sol - gel method and vacuum annealing process. By changing the annealing process to adjust the proportion of vanadium dioxide in the film to achieve changes in its phase change electric field threshold. And It had been found that the electric field intensity transformation point was reduced from $1.8 \mathrm{MV} / \mathrm{M}$ to $0.4 \mathrm{MV} / \mathrm{M}$ and Phase change electric field strength decreased by about 4 times. It has also been found that the resistance abrupt multiplier decreased as the field phase change point decreased and the change range of the phase change was 2 $\times 10^{3} \sim 1 \times 10^{2}$.
\end{abstract}

\section{Introduction}

Vanadium dioxide can be reversibly changed from monoclinic structure to tetragonal rutile structure at near room temperature (about $68^{\circ} \mathrm{C}$ ) [1], and its optical, magnetic, electrical properties have also mutated with the crystal structure. This excellent optical electromagnetism makes $\mathrm{VO}_{2}$ a great potential in smart windows [4], electrical switches [5], terahertz devices [6].

With the continuous research of vanadium dioxide in recent years, the control technology of vanadium dioxide phase transition temperature has been basically mature, mainly in the following three ways: adjust the applied stress[8-9], control the microstructure[10-12] and ion doping[13-15]. But the control of the phase change field strength was basically not studied, There were two main reasons for this. On the one hand, most of the applications of vanadium dioxide were mainly based on the theoretical basis of the thermo-phase transition of vanadium dioxide. On the other hand, the effect of ion doping on the transformation field of vanadium dioxide was not obvious. In this way, the successful development of a preparation of vanadium dioxide film adjustable phase change electric field technology was very meaningful.

The regulation of the phase change electric field can also be divided into three methods: regulating the external stress, controlling the microstructure and ion doping. However, due to ion doping on the vanadium dioxide electric field threshold control was not obvious, so the control of micro-morphology was preferred. For the control of micro-morphology can be also divided into the following categories: control the film's compactness, control the size of grain and control the content of $\mathrm{VO}_{2}$. For the electrical performance, the film should have a high density. In the case of grain size, the size of the grains could change the phase transition point of the electric field, the principle was similar to that of the $\mathrm{ZnO}$ nano-particles, but it was difficult to prepare by using solgel. In contrast, the simpler method of controlling the intensity transition point of the electric field was to change the content of $\mathrm{VO}_{2}$. the amount of $\mathrm{V}_{2} \mathrm{O}_{5}$ reduced to $\mathrm{VO}_{2}$ was controlled by using the vacuum annealing process. So that the proportion of controlled $\mathrm{VO}_{2}$ in the film can be achieved. And so the purpose of controlling the intensity transition point of the vanadium dioxide electric field was realized. 
In this paper, $\mathrm{VO}_{2}$ thin films were prepared by inorganic sol-gel method and vacuum annealing process. The phase change electric field was prepared by changing the vacuum annealing temperature on the $\mathrm{Al}_{2} \mathrm{O}_{3}$ ceramic substrate. And the temperature phase transition point test and the electric field intensity transformation point test were carried out for each sample. It was found that the phase transition point of vanadium dioxide was reduced from $1.8 \mathrm{MV} / \mathrm{M}$ to $0.4 \mathrm{MV} / \mathrm{M}$, and the phase transition electric field was reduced by more than 4 times. It was also found that with the decrease of phase transition point of electric field intensity, the resistance abrupt multiplier was reduced $\left(2 \times 10^{3} \sim 1 \times 10^{2}\right)$.

\section{Experimental Process}

\section{Preparation of VO2 Thin Films}

\section{Preparation of V2O5 sol}

The $\mathrm{VO}_{2}$ thin films were prepared by inorganic sol-gel method and vacuum annealing process. The specific experimental procedure was as follows: take $5 \mathrm{~g} \mathrm{~V}_{2} \mathrm{O}_{5}$ (purity 99.9\%) in the crucible into the $850{ }^{\circ} \mathrm{C}$ muffle furnace for $15 \mathrm{~min}$. Take $250 \mathrm{ml}$ of deionized water in a beaker, the beaker placed on a magnetic stirrer, select the speed of $2800 \mathrm{r} / \mathrm{min}$, the molten vanadium pentoxide was rapidly introduced into deionized water, after stirring for one minute, the beaker was placed on a constant temperature stirrer at a temperature of $60{ }^{\circ} \mathrm{C}$ for $2 \mathrm{~h}$. At last the solution was allowed to stand for 48 h.

\section{Cleaning of the substrate}

The substrate was placed in a mixed solution (8:2) of anhydrous ethanol and acetone for $1 \mathrm{~h}$, and then placed in concentrated solution (1:9) of concentrated hydrochloric acid and deionized water for $1 \mathrm{~h}$. Finally rinse off with deionized water.

\section{Pull the coating}

The cleaned substrate was placed on the clip of the pull-up coating machine, select the coating parameters: The descending speed is $2000 \mathrm{um} / \mathrm{s}$, the standing time in the sol is $100 \mathrm{~s}$ and the pulling speed is $2000 \mathrm{um} / \mathrm{s}$, after the completion of a pull, the vanadium pentoxide wet film was dried in a $100{ }^{\circ} \mathrm{C}$ oven for $15 \mathrm{~min}$ and then subjected to a second coating and circulated 4 times. In order to increase its adhesion[16], the coated vanadium pentoxide dried film was dried in a $200{ }^{\circ} \mathrm{C}$ oven for $200 \mathrm{~min}$.

\section{Vacuum annealing}

Vacuum annealing is the most critical step in the preparation of phase change electric field threshold adjustable vanadium dioxide, where annealing temperature and annealing vacuum are important for $\mathrm{V}_{2} \mathrm{O}_{5}$ to be fully reduced to $\mathrm{VO}_{2}$. During the annealing process, the sample is reduced from $\mathrm{V}_{2} \mathrm{O}_{5}$ to $\mathrm{VO}_{2}$, which is a process for the precipitation of oxygen. If the annealing temperature is low enough, when a part of the sample $\mathrm{V}_{2} \mathrm{O}_{5}$ converted to $\mathrm{VO}_{2}$, the precipitation of oxygen in the annealing furnace will reduce the vacuum, and thus fail to restore the conditions of $\mathrm{VO}_{2}, \mathrm{~V}_{2} \mathrm{O}_{5}$ can only be reduced to $\mathrm{V}_{6} \mathrm{O}_{13}$. So the level of control of the annealing temperature can be indirectly controlled $\mathrm{V}_{2} \mathrm{O}_{5}$ converted to the amount of $\mathrm{VO}_{2}$, and thus control the content of $\mathrm{VO}_{2}$ in the film. The specific implementation process was as follows: three samples were annealed at $480{ }^{\circ} \mathrm{C}$, $500{ }^{\circ} \mathrm{C}$ and $520^{\circ} \mathrm{C}$, respectively, the annealing time was $8 \mathrm{~h}$, heating and cooling rate was $11^{\circ} \mathrm{C} / \mathrm{min}$ and the vacuum was $50 \mathrm{~Pa}$ to $100 \mathrm{~Pa}$.

\section{Test Methods}

Two different methods were used to test the temperature transition point and the electric field strength change point of the material. 


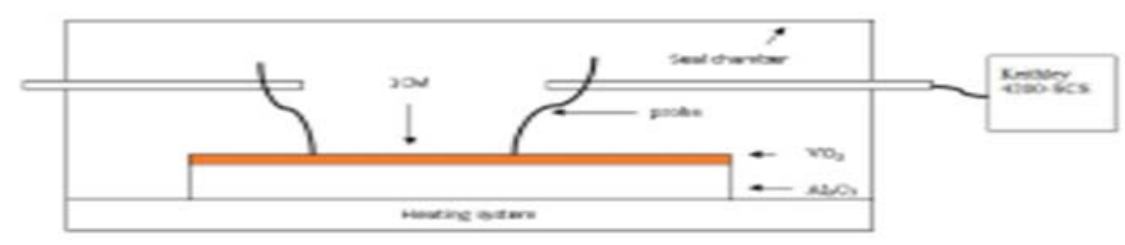

Fig1.Temperature phase change point test schematic

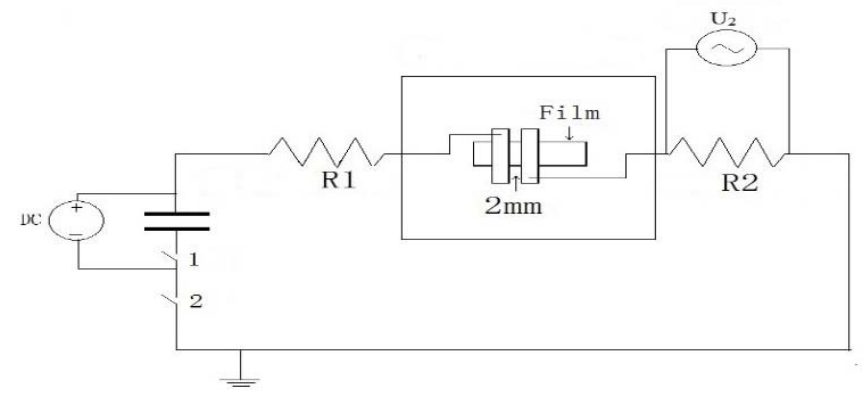

Fig 2. electric field strength phase change point test system schematic diagram

Three temperature samples were tested using a two-probe test system, specific test chart shown in Figure 1. Two probe spacing $1 \mathrm{CM}$, and the bottom of the substrate was the temperature control system, the accuracy of temperature was $0.5^{\circ} \mathrm{C}$. In order to ensure the sensitivity of the temperature test system to temperature, the whole system was sealed in a heat preservation chamber and insulated from the outside. Finally Keithley 4200-SCS was used to collect test data.

The high voltage test system was used to test the phase transition point of the electric field, specific test chart was showed in Figure 2. A large capacitor was used as a voltage source, this was mainly because on the one hand large capacitors was used to avoid damage to high voltage sources, on the other hand in high pressure environment, high voltage output was instability. During the test,fist turn off the switch 1 and turn on the switch 2 to charge the capacitor, and then turn on the switch and turn off the switch 2 to test the material. Moreover current limiting resistor $\mathrm{R}_{1}$ resistance was $30 \mathrm{M} \Omega$, and the sampling resistor $\mathrm{R}_{2}$ resistance was $1000 \Omega$. In addition the fixture was made of copper electrode, the size was $10 \mathrm{~mm} \times 10 \mathrm{~mm} \times 50 \mathrm{~mm}$, the distance between the two fixtures was $2 \mathrm{~mm}$. Furthermore the two electrodes in contact with the surface of the material, the rest were made all over the chamfer, to avoid cutting-edge discharge, at the same time, in order to avoid flashover due to high voltage flash [17], fill in the temperature control system SF6. The sample resistance was measured by the $\mathrm{DC}$ output voltage $\mathrm{U}_{0}$ and the oscilloscope voltage $\mathrm{U}_{2}$ calculated by Equation 1, and the phase change electric field was calculated by Equation 2

$$
\begin{gathered}
\frac{1}{\mathrm{R}}=\frac{\mathrm{U}_{2}}{\mathrm{U}_{0} \mathrm{R}_{2}-\mathrm{U}_{2} \mathrm{R}_{1}-\mathrm{U}_{2} \mathrm{R}_{2}} \\
\mathrm{E}_{\mathrm{T}}=\frac{\mathrm{V}_{\mathrm{T}}}{\mathrm{d}}
\end{gathered}
$$

\section{Test Results and Analysis}

Fig.3(a) showed the relationship between the temperature transition point at different annealing temperatures. It was also showed that as the annealing temperature decreases, the resistance decreases at room temperature. For example, when the vacuum annealing temperature was $520{ }^{\circ} \mathrm{C}$, the resistance at room temperature was $10 \mathrm{M} \Omega$, when the vacuum annealing temperature was 
$500{ }^{\circ} \mathrm{C}$, the resistance at room temperature was $0.6 \mathrm{M} \Omega$, and when the vacuum annealing temperature was $480{ }^{\circ} \mathrm{C}$, the resistance at room temperature was $0.6 \mathrm{M} \Omega$, The main reason for this phenomenon was the lower the annealing temperature, the less the content of $\mathrm{VO}_{2}$ in the film, and another reason was other valence of the vanadium oxide resistance was lower than $\mathrm{VO}_{2}$ at room temperature. At the same time, we also found that the temperature transition point of the three samples did not change, indicating that this method does not affect the material phase transition temperature, but would change the material before and after the transformation of the resistance value.

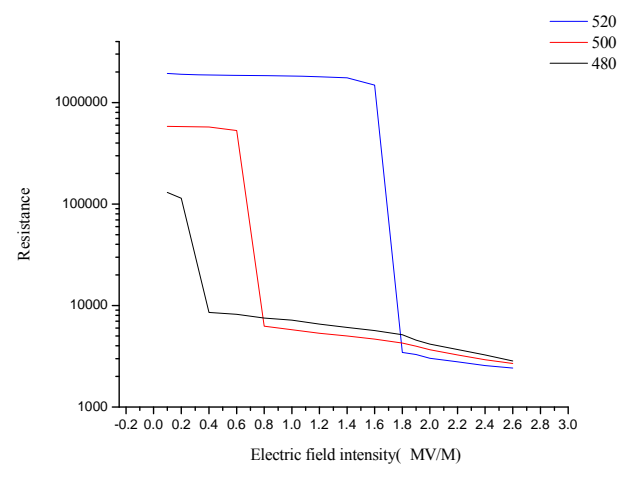

(a)

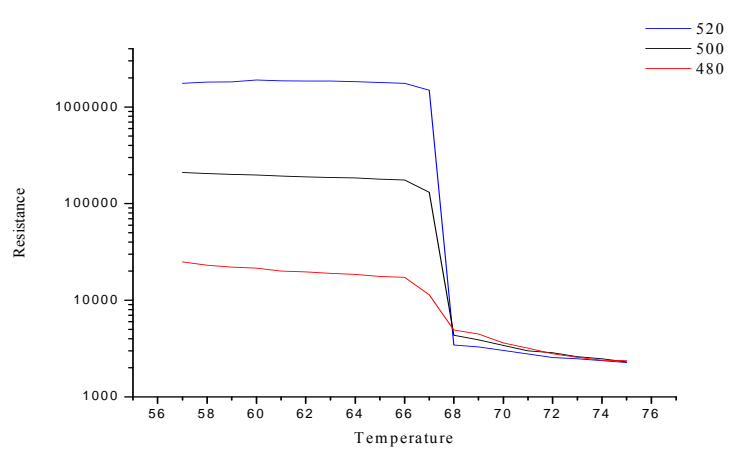

(b)

Fig 3 Temperature (a) and electric field strength (b) transformation point test chart

Figure 3 (b) shows the relationship between the phase transition point of the electric field at different annealing temperatures. It could be seen from Figure 3 (b) with the annealing temperature decreases, the electric field intensity transition point was also constantly reduced. When the annealing temperature was $520^{\circ} \mathrm{C}$, the electric field intensity transition point was $1.8 \mathrm{MV} / \mathrm{M}$, when the annealing temperature was $500{ }^{\circ} \mathrm{C}$, the electric field intensity transition point was $0.8 \mathrm{MV} / \mathrm{M}$ and when the annealing temperature was $480{ }^{\circ} \mathrm{C}$, the electric field intensity transition point was 0.4 $\mathrm{MV} / \mathrm{M}$. But at the same time we also found that with the $\mathrm{VO}_{2}$ thin film electric field strength transformation point of the reduction, the phase change factor also decreased. For example, When the annealing temperature was $500{ }^{\circ} \mathrm{C}$, the resistance change was $3 \times 10^{2}$ times and when the annealing temperature was $480{ }^{\circ} \mathrm{C}$, the resistance change was $1 \times 10^{2}$ times. The main reason for this phenomenon was that the reduction of the electric field intensity transition point was achieved by reducing the content of $\mathrm{VO}_{2}$ in the film, the lower the content of $\mathrm{VO}_{2}$ in the film, the less energy it needed to excite the electric field. However, with the decrease of $\mathrm{VO}_{2}$ content in the film, the phenomenon of phase change was less obvious because the vanadium oxide containing more valence in the film reduced the resistance value of the film at room temperature. So the phase transition factor decreased as the phase transition point of the electric field decreased. The Fig 3 (b) also showed that by using this method of preparation reduced the intensity transition point of the $\mathrm{VO}_{2}$ for electric field was below $1 \mathrm{MV} / \mathrm{M}$, about $0.4 \mathrm{MV} / \mathrm{M}$, which was reduced more than 4 times.

\section{Conclusion}

In this paper, three samples with annealing temperature of $520{ }^{\circ} \mathrm{C}, 500{ }^{\circ} \mathrm{C}$ and $480{ }^{\circ} \mathrm{C}$ were prepared on the $\mathrm{Al}_{2} \mathrm{O}_{3}$ ceramic substrate by using inorganic sol-gel and vacuum annealing, and the temperature transformation point test and the electric field intensity transformation point test were carried out for the three samples respectively. It was found that the vanadium dioxide thin film prepared by using this method did not affect the phase transition temperature, and all the phase 
transition temperature of the three samples were $68^{\circ} \mathrm{C}$, but it would affect the phase change factor $\left(2 \times 10^{3} \sim 1 \times 10^{2}\right)$. At the same time, the phase transition point of the electric field intensity of the three samples showed a significant change. It was found that the phase transition point of the electric field decreased from $1.8 \mathrm{MV} / \mathrm{M}$ to $0.4 \mathrm{MV} / \mathrm{M}$ with the decrease of annealing temperature. In this experiment, it was proved that the phase transition point of the electric field could be adjusted, and the phase transition point of the $\mathrm{VO}_{2}$ electric field was reduced to less than $1 \mathrm{MV} / \mathrm{M}$, about 0.4 $\mathrm{MV} / \mathrm{M}$, and the field strength was reduced About 4 times by using this method. In summary, it was of great significance to extend the application range of vanadium dioxide by using this method.

\section{Reference}

[1] Morin F J. Oxides which show a metal -to-insulator transition at the Neel temperature, J. Phy. Rev. Lett. 3(1) (1959) 34-36.

[2] Xiong Ying, Wen Qi, Tian Wei, Mao Qi, Chen Zhi, Yang Qinghui, Jing Yulan.Study on electrical properties of silicon-based vanadium dioxide transition film, J. Acta Physica Sinica. 64 (1) (2015) 017102

[3] Ruzmetov D, Zawilski K T, Narayanamurti V, et al. Structure-functional property relationships in rf-sputtered vanadium dioxide thin films, J. Journal of Applied Physics. 102(11) (2007) 113715 - 113715-7.

[4] Huang Zhangli, Chen Sihai, LU Chaohong,et al. Infrared characteristices of $\mathrm{VO}_{2}$ thin film for smart window and laser protection applications, J. Applied Physics Letters. 101 (19) (2012) 191905.

[5] Stefanovich G, Pergament A, Stefanovich D. Electrical switching and Mott transition in VO2, J. Journal of Physics Condensed Matter. 12(41) (2000) 8837.

[6] Qiu D H, Wen Q Y, Yang Q H, et al. Growth of vanadium dioxide thin films on Pt metal film and the electrically-driven metal-insulator transition charact-eristics of them, J. Acta Physica Sinica Chinese Edition. 62(21) (2013) 217201-590.

[7] Wen Q Y, Zhang $\mathrm{H} \mathrm{W}$, Yang Q H, et al. Terahertz metamaterials with $\mathrm{VO}_{2}$ cut-wires for thermal tunability, J. Applied Physics Letters,. 97(2) (2010) 021111-021111-3.

[8] Y.Muraoka and Z. Hiroi, Metal\&\#x2013; insulator transition of VO2 thin films grown on TiO2 (001) and (110) substrates, J. Appl Phys Lett. 80 (2002) 583-585.

[9] F. C. Case, Modifications in the phase transition properties of predeposited $\mathrm{VO}_{2}$ films, J. Journal of Vacuum Science \& Technology a-Vacuum Surfaces and Films. 2 (1984) 1509-1512.

[10] M. B. Sahana, M. S. Dharmaprakash and S. A. Shivashankar, Advances in thermochromic vanadium dioxide films, J. Mater chem. 12 (2002) 333-338.

[11] Luo Y Y, Zhu L Q, Zhang Y X, et al. Optimization of microstructure and optical properties of $\mathrm{VO}_{2}$ thin film prepared by reactive sputtering, J. Journal of Applied Physics. 113(18) (2013) 1191.

[12] Whittaker L, Jaye $\mathrm{C}, \mathrm{Fu} \mathrm{Z}$, et al. Depressed phase transition in solution-grown $\mathrm{VO}_{2}$ nanostructures, J. Journal of the American Chemical Society. 131(25) (2009) 8884.

[13] Tan X, Yao T, Long R, et al. Unraveling Metal-insulator Transition Mechanism of $\mathrm{VO}_{2}$ Triggered by Tungsten Doping, J. Scientific Reports. 2(6) (2012) 466.

[14] Whittaker L, Wu T L, Patridge C J, et al. Distinctive finite size effects on the phase diagram and metal-insulator transitions of tungsten-doped vanadium(IV) oxide, J. Journal of Materials Chemistry. 21(15) (2011) 5580-5592. 
[15] Patridge C J, Whittaker L, Ravel B, et al. Elucidating the Influence of Local Structure

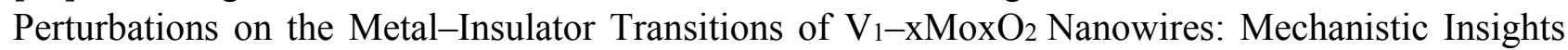
from an X-ray Absorption Spectroscopy Study, J. Journal of Physical Chemistry C. 116(5) (2012) 3728-3736.

[16] Chae B G, Kim H T, Yun S J, et al. Highly oriented $\mathrm{VO}_{2}$ thin films prepared by sol-gel deposition method, J. Electrochemical and Solid-State Letters. 9(1) (2005) C12-C14.

[17] Wang Caixiong,Tang Zhiguo,Chang Wenzhi,et al. Experimental Study on Development Characteristics of Point Discharge in GIS , J. Power System Technology . 35(11) (2011) 157-162. 